\title{
The Combined Use of SLAM Laser Scanning and TLS for the 3D Indoor Mapping
}

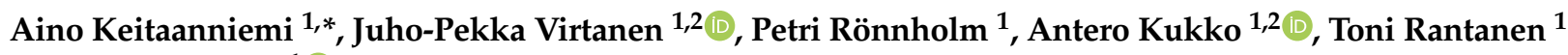 \\ and Matti T. Vaaja ${ }^{1}$ (D) \\ 1 Department of Built Environment, School of Engineering, Aalto University, P.O. Box 14100, \\ 00076 Aalto, Finland; juho-pekka.virtanen@aalto.fi (J.-P.V.); petri.ronnholm@aalto.fi (P.R.); \\ antero.kukko@nls.fi (A.K.); toni.rantanen@aalto.fi (T.R.); matti.t.vaaja@aalto.fi (M.T.V.) \\ 2 Finnish Geospatial Research Institute FGI, Geodeetinrinne 2, 02430 Masala, Finland \\ * Correspondence: aino.keitaanniemi@aalto.fi
}

Citation: Keitaanniemi, A.; Virtanen, J.-P.; Rönnholm, P.; Kukko, A.; Rantanen, T.; Vaaja, M.T. The Combined Use of SLAM Laser Scanning and TLS for the 3D Indoor Mapping. Buildings 2021, 11, 386. https://doi.org/10.3390/ buildings11090386

Academic Editor: Emanuele Brunesi

Received: 1 July 2021

Accepted: 24 August 2021

Published: 28 August 2021

Publisher's Note: MDPI stays neutral with regard to jurisdictional claims in published maps and institutional affiliations.

Copyright: (c) 2021 by the authors. Licensee MDPI, Basel, Switzerland. This article is an open access article distributed under the terms and conditions of the Creative Commons Attribution (CC BY) license (https:// creativecommons.org/licenses/by/ $4.0 /)$.

\begin{abstract}
An efficient 3D survey of a complex indoor environment remains a challenging task, especially if the accuracy requirements for the geometric data are high for instance in building information modeling (BIM) or construction. The registration of non-overlapping terrestrial laser scanning (TLS) point clouds is laborious. We propose a novel indoor mapping strategy that uses a simultaneous localization and mapping (SLAM) laser scanner (LS) to support the building-scale registration of nonoverlapping TLS point clouds in order to reconstruct comprehensive building floor/3D maps. This strategy improves efficiency since it allows georeferenced TLS data to only be collected from those parts of the building that require such accuracy. The rest of the building is measured with SLAM LS accuracy. Based on the results of the case study, the introduced method can locate non-overlapping TLS point clouds with an accuracy of $18-51 \mathrm{~mm}$ using target sphere comparison.
\end{abstract}

Keywords: simultaneous localization and mapping (SLAM) 1; non-overlap 2; terrestrial laser scanning (TLS) 3; point clouds 4; 3D mapping 5

\section{Introduction}

The 3D mapping of indoor environments is beneficial for many applications, such as the documentation of constructions or historical buildings (e.g., [1,2]), building diagnostics (e.g., [3]), the life cycle of buildings (e.g., [4]), and building information modeling (BIM) (e.g., [5-7]). There are many methods with which to collect data from indoor environments, such as terrestrial laser scanning (TLS) (e.g., [8,9]), photogrammetry (e.g., [10,11]), using depth cameras (e.g., [12,13]), and using simultaneous localization and mapping (SLAM) laser scanners (LSs) (e.g., $[14,15])$. Not all of the techniques are suitable in every indoor mapping application because of their limitations. Photogrammetry is time consuming and often hampered by ambient light. Depth cameras require specific lighting. The SLAM LS is currently at centimeter level accuracy. Though TLS is accurate, it is expensive and the most limiting factor is its static data collection principle, which only provides a limited number of observation points in the capturing of often polymorphic structures $[3,16]$.

For years TLS has been widely used in the 3D measurement of indoor environments. It enables high-quality point clouds with high accuracy $(0.1-5 \mathrm{~mm})$ and precision $(0.6-4 \mathrm{~mm})$, and a high level of detail [17]. As a result, it has become common practice to utilize TLS as a reference system when testing, for example, more affordable scanning systems (e.g., [18]). However, in a large and complex indoor environment, TLS requires a multitude of scanning positions in order to obtain sufficient data. This increases the amount of time required to cover the whole environment. Besides this, when the measurements of the indoor space required being georeferenced, it becomes a necessity to collect additional data with TLS and/or traditional surveying/measuring methods in order to establish a common coordinate system and tie the observations to that. In particular, moving from one 
room to another typically requires extra work in order to ensure accurate georeferencing. This also increases the time spent on the data collection [19-21]. In indoor environments, it is laborious to register non-overlapping spaces together by creating extra TLS scans to connect non-overlapping point clouds (e.g., the spaces/rooms at different ends of a corridor). When the only purpose is the registration of the non-overlapping data, it creates excessive unnecessary work, measurements, data, time cost, etc. Another option for registering these non-overlapping point clouds is to use geodetic surveying methods to measure tie points, which is time consuming and also needs extra equipment and expertise.

SLAM LSs have been used for indoor mapping for some years; they have been used in, for example, construction sites, modern buildings, cultural heritage sites, and open spaces (e.g., [14,22,23]). The SLAM LSs are fast for data collection because they are mostly handheld or backpack systems and the data collection only requires walking around the environment. Besides this, it works without a global navigation satellite system (GNSS), which enables the use of a mobile laser scanner in environments that do not have satellite coverage. A SLAM LS is typically designed to be as simple as possible to use. The user does not have to be an expert, though application requirements and the optimal measurement trajectory should preferably be considered/understood. However, based on the results of prior studies, the accuracy of SLAM LSs are at the centimeter level [22,24-26]. While several papers mention the efficiency of SLAM systems in obtaining comprehensive data from complex indoor environments, we were not successful in finding earlier works that utilize a SLAM LS as a reference frame for other point cloud data sets $[14,27,28]$. The integration of these two techniques would solve the laboriousness of acquiring georeferenced TLS data and overcoming the reduced accuracy of SLAM. It would add even more productivity and quality as the new technologies have done during past years for construction $[29,30]$

This study aims to introduce a novel strategy for the registration of non-overlapping TLS data with the support of SLAM LS data in order to collect geometrically coherent building interior data. This enables more effective data collection in large and complex buildings because it is possible to prioritize spaces according to their need for point cloud accuracy. The spaces that demand the highest accuracy can be measured with TLS. In large buildings, it is not necessarily demanded to have millimeter-level accuracy in every space of the building, the high-accuracy spaces can be registered to each other by using a rapid and easily adaptable SLAM LS point cloud. By combining the advantages of both the TLS and SLAM LS methods, we can not only execute the data collection of large buildings more effectively and get the demanded accuracy for the requested spaces but can also reconstruct the overall geometry of the floor plans or interiors. This approach creates comprehensive point cloud information on the environment. More precisely, the aim is to establish both the accuracy of the non-overlapping TLS point cloud registration with SLAM LS data support and how much the shorter SLAM LS walking path influences the accuracy of non-overlapping TLS point clouds. We present the method employed, demonstrate its use in an indoor mapping case, and investigate the 3D mapping accuracy.

\section{Related Studies}

\subsection{Measurement Methods for the Indoor Environment}

There are many methods for measuring indoor environments, such as TLS, using a SLAM LS, using a depth camera, using a millimeter-wave radar, and photogrammetry. Mapping indoor spaces with depth cameras has been studied (e.g., by [12]). The method requires optimization for lighting and scanning speed. It can be used for modeling small physical objects within a room or reconstructing the general framework of rooms while ignoring the details. [12] Chen et al. [27] compared SLAM LS sensors and depth cameras for indoor mapping and found out that the accuracies of the sensors were at the centimeter level throughout $40 \mathrm{~m}$. Based on the study, the depth camera resulted in the lowest point density and the weakest accuracy [27]. The state-of-the-art millimeter-wave radar SLAM systems provide a dense grid map and have accuracy close to that of a SLAM LS [31]. 
The strength of such systems is that mapping in difficult environments containing smoke or dust is possible.

Photogrammetry and TLS are widely used methods for indoor mapping. Photogrammetry uses photographs to create a $3 \mathrm{D}$ point cloud of the environment by measuring the object features in different images to create a geometric representation of the object. Photogrammetry enables high-resolution textures and high point density, even with non-metric cameras [10]. For this reason, it has been used for many applications-such as construction progress monitoring, as-built modeling and documentation (e.g., [32,33]). Masiero et al. [34] compared low-cost photogrammetry and using a SLAM LS with a TLS reference for the 3D reconstruction of a medieval bastion. Based on the results, photogrammetry had weaker results because of scale errors [34]. Besides this, the lack of texture in many indoor materials can cause problems for finding tie points between images.

TLS is one type of laser scanning and it creates a 3D point cloud with Light Detecting and Ranging (LiDAR). It is capable of collecting millions of points in a short period of time. For this reason, it has been used in many applications-such as project monitoring, building diagnostics, progress control, change detection, quality control, creating part-built and as-built models (e.g., [3,35]). For indoor mapping, TLS is a good option because of its ability to generate high point density and good accuracy [36]. However, on its own it is an expensive method for 3D mapping in large and complex indoor environments $[3,33]$.

The SLAM LS sensors can be classified into three categories based on the platform of operation: a handheld, backpack, or trolley sensor. Of these categories, handheld and backpack LS sensors are great options for mapping indoor environments. They have better adaptation to typical indoor and construction features-such as corners, steps, stairways, and other geometric irregularities in the environment-than trolleys. The accuracy of handheld and backpack sensors is sufficient for the majority of their applications [37]. In Section 2.3 we concentrate on the earlier literature on using SLAM LS for indoor mapping.

\subsection{Georeferencing Indoor TLS Point Clouds}

Georeferencing can be categorized into two main types: indirect and direct georeferencing. An indirect approach necessitates external tie points and observations in order to orientate the acquired data to a target coordinate frame. Indirect georeferencing in the case of TLS point clouds is commonly performed with two- or three-dimensional control targets, which are specially designed for the purpose. The locations of these targets are typically measured with traditional surveying tools, for example, with a total station. This information is then integrated into the TLS point cloud.

Direct georeferencing uses integrated sensors, such as the GNSS and the inertial measurement unit (IMU), to collect sensor location and orientation information, such as the collected airborne laser scanning (ALS) or outdoor mobile laser scanning (MLS). In some cases, GNSS and IMU solutions can be improved by wheel odometry or visual odometry. The data from these sensors are then integrated with point cloud data [38]. Such a system cannot be directly used indoors due to GNSS signal loss an alternative approach is required. For such purposes, using a SLAM LS provides a fairly competent approach.

In addition to indirect and direct georeferencing, there is the possibility to use a datadriven approach. In this case, an a priori map is needed (i.e., georeferenced point cloud data), which can be utilized as a reference to a new TLS point cloud. The new TLS point cloud is matched to the reference, and the TLS point cloud will thus be georeferenced [38].

\subsection{SLAM Laser Scanning of the Indoor Environment}

Maboudi et al. [14] studied the system quality by comparing a Viametris iMS3D and a GeoSLAM Zeb-revo SLAM LS with a TLS reference for 3D indoor mapping. Based on the study, the differences and errors from the plane surface were small with SLAM sensors. Besides this, they noted that the size of the room influences the trajectory of a SLAM LS. Tucci et al. [22] examined indoor mapping systems-such as Kaarta Stencil, Leica Pegasus Backpack, and GeoSLAM Zeb-revo-in an old fortress. The systems were 
compared with a TLS reference. Based on the results, the differences to the TLS were at the centimeter level and the Zeb-revo had the smallest differences $(4 \mathrm{~cm})$. Lehtola et al. [28] compared indoor scanning methods in several indoor environments, such as a hall, a twostory garage, and a big open space. They investigated the performance of a Matterport, NavVis (M3), Zeb1, Stencil, Leica Pegasus, Aalto VILMA, FGI SLAMMER, and a Würzburg backpack and created a ranking of the sensors based on comparison with the TLS reference. Besides this, Chen et al. [27] compared the accuracies of the Matterport, SLAMMER, and FGI NAVIS. The results were at the centimeter level in complex indoor environments. However, the point density and accuracy were weakest with the Matterport.

Sirmacek et al. [24] compared the GeoSLAM Zeb1 with the TLS reference within a fire station set. Based on the results, the small objects were difficult to detect, even though the accuracy was at the centimeter level. However, the system was concluded to be sufficient for rough repair planning or cadastre measuring. Nocerino et al. [39] investigated the performance of a GeoSLAM Zeb-revo and a Leica Pegasus Backpack in two sites, which were a two-floor building and an open city square. The systems were compared with TLS and the results were within expectations, and the given specifications of the manufacturers were within the standard error of 30-300 $\mathrm{mm}$ when compared with the results. Salgues et al. [15] instead evaluated a GeoSLAM Zeb-revo RT and a GreenValley LiBackpack C50 by comparing the data with a TLS reference. The data was collected from a tower, museum, and a laboratory, and the results for the systems under scrutiny were mutually comparable. The accuracy was up to $1 \mathrm{~cm}$, but they observed high measurement noise. Furthermore, the point densities in the data from the kinematic systems were lower than that of the static TLS. Chiabrando et al. [25] explored the use of a Zeb-revo RT for heritage documentation. The resulting data differed from the TLS reference by $3-5 \mathrm{~cm}$, and the colorization quality of the point cloud was concluded to be weak.

Elsewhere a SLAM LS has been tested for cultural heritage, modeling indoors, and in combinations of indoor and outdoor spaces [26,40]. Di Filippo et al. [26] examined the Zeb-revo system when used for modeling a complex historical site. A final point cloud was created for over 50 rooms amounting to $3000 \mathrm{~m}^{2}$ in $2.5 \mathrm{~h}$ with centimeter accuracy. Zlot et al. [40] analyzed the efficiency of the Zeb1 system for mapping a large and complex cultural heritage site. A SLAM LS was found to enable measurements from otherwise hard-to-reach areas. However, the data from open areas created a $10 \mathrm{~cm}$ difference in comparison to an aerial image reference.

The SLAM LS systems have also been tested for more specific applications: as part of as-built BIM and for creating strata title plans or floor plans. In the BIM applications, SLAM has been tested as a tool for data collection and the results reported are promising. The SLAM systems have been shown to work in BIM, and they save time [41,42]. It has also been proven that a SLAM LS can be used for strata title plans and floor plan creation, and using a SLAM LS is easier and faster than doing those plans with a distometer $[43,44]$. To go even further, Nikoohemat et al. [45] created a pipeline to execute change detection in a 3D cadastre with a SLAM LS. All the sensors and study sites are shown in Table 1.

Table 1. The study sites and sensors of various authors. are cited.

\begin{tabular}{lll}
\hline Author & Sensors & Study Site \\
\hline Maboudi et al. [14] & A Viametris iMS3D and a GeoSLAM Zeb-reve & $\begin{array}{l}\text { Three rooms on the same floor of a } \\
\text { modern building }\end{array}$ \\
& $\begin{array}{l}\text { A Matterport, NavVis M3, GeoSLAM Zeb1, Kaarta } \\
\text { Sehtolil, Leica Pegasus, Aalto VILMA, FGI }\end{array}$ & $\begin{array}{l}\text { A hall, a two-story garage, and a big open } \\
\text { space/room }\end{array}$ \\
Sirmacek et al. [24] & $\begin{array}{l}\text { SLAMER and a Würzburg backpack } \\
\text { A GeoSLAM Zeb1 }\end{array}$ & A fire station \\
Nocerino et al. [39] & $\begin{array}{l}\text { A GeoSLAM Zeb-revo and a Leica Pegasus } \\
\text { A GeoSLAM Zeb-revo RT and a GreenValley } \\
\text { Salgues et al. [15] }\end{array}$ & A two-floor building and an open city square \\
& LiBackpack C50 & A tower, museum, and a huge laboratory \\
\hline
\end{tabular}


Table 1. Cont.

\begin{tabular}{lll}
\hline Author & Sensors & Study Site \\
\hline Chen et al. [27] & A Matterport 3D camera, FGI SLAMMER, and an & An L-shaped corridor and an open style library \\
& FGI NAVIS & \\
Tucci et al. [22] & A Kaarta Stencil, Leica Pegasus Backpack, and a & An old fortress \\
Chiabrando et al. [25] & GeoSLAM Zeb-revo & A GeoSLAM Zeb-revo RT \\
Di Filippo et al. [26] & A GeoSLAM Zeb-revo & A gothic palace in ruins \\
Micoli et al. [46] & A GeoSLAM Zeb-revo & A late Roman circus in Milan \\
Zlot et al. [40] & A GeoSLAM Zeb1 & A large outdoor cultural heritage site, Peel Island \\
Sepasgozar et al. [41] & A GeoSLAM Zeb1 & A campus building \\
Thomson et al. [42] & A Viametris i-MMS and GeoSLAM Zeb1 & The ground floor of a campus building \\
Tang et al. [23] & A self-built SLAM LS system & A large indoor parking lot \\
Samad et al. [43] & A GeoSLAM Zeb1 & A hostel building \\
Russhakim et al. [44] & A GeoSLAM Zeb-revo & One floor of a campus building \\
Nikoohemat et al. [45] & A GeoSLAM Zeb-revo and a backpack system & One floor of a modern building \\
\hline
\end{tabular}

\subsection{The Data Integration of TLS and SLAM LSs}

The integration of datasets is important for 3D building modeling, navigation applications, and BIM. Numerous studies have been published on the topic, such as methods to register different data sources, methods to create BIM models, and methods to create comprehensive navigation solutions. Altuntas et al. [47] have combined TLS datasets from outdoors and indoors with an iterative closest point (ICP) calculation with the overlapping areas of the datasets. Wen et al. [48] studied a method where the point clouds were segmented and extracted into lines, and the line sets of different point clouds were used to register the point clouds together, applying ICP [48]. Serrano et al. [49] tested using unmanned aerial vehicles (UAVs) to integrate indoor and outdoor data by using the GNSS of the UAVs for localization outdoors while indoors the localization was based on SLAM [49]. There have also been attempts to integrate indoor and outdoor data with BIM models and geographical information system (GIS) datasets (e.g., [50]). The research has shown that the integration of datasets from different sources can improve the accuracy, continuity, integrity, and availability of the solutions [49].

The use of a SLAM LS has been combined with using UAVs and TLS in several applications, such as cultural heritage and slope modeling [25,46,51-53]. In the work of Chiabrando et al. [25], a total station network was utilized to obtain global target positions that were then utilized for a TLS survey, photogrammetric reconstruction, and SLAM campaign. In the work of Micoli et al. [46], both TLS and SLAM sections were combined, with SLAM being applied in environments that would be too laborsome for TLS. The integration of the methods created good 4D models. In addition to these, Sammartano and Spanò [51] combined SLAM LS with UAVs and got centimeter accuracy. In the work of Vanneschi et al. [53], a SLAM LS was used to fill in occluded areas of TLS and the error was less than $1 \mathrm{~cm}$. Chiabrando et al. [52] studied the integration of a SLAM LS into a UAV. As a result, it was possible to integrate a SLAM LS with a UAV in a complex cultural heritage site. With this method, it is possible to integrate images from different times or without targets into one photogrammetric model [52].

\section{Materials and Methods}

\subsection{TLS Registration with SLAM in Large Buildings}

We propose that the non-overlapping TLS point clouds of different rooms can be registered with the aid of a SLAM LS, even when the TLS point clouds do not have overlapping data. In Figure 1, this is conceptualized and compared with an ordinary TLS measurement campaign. Naturally, a sufficient overlap between SLAM LS data and TLS data is essential. 

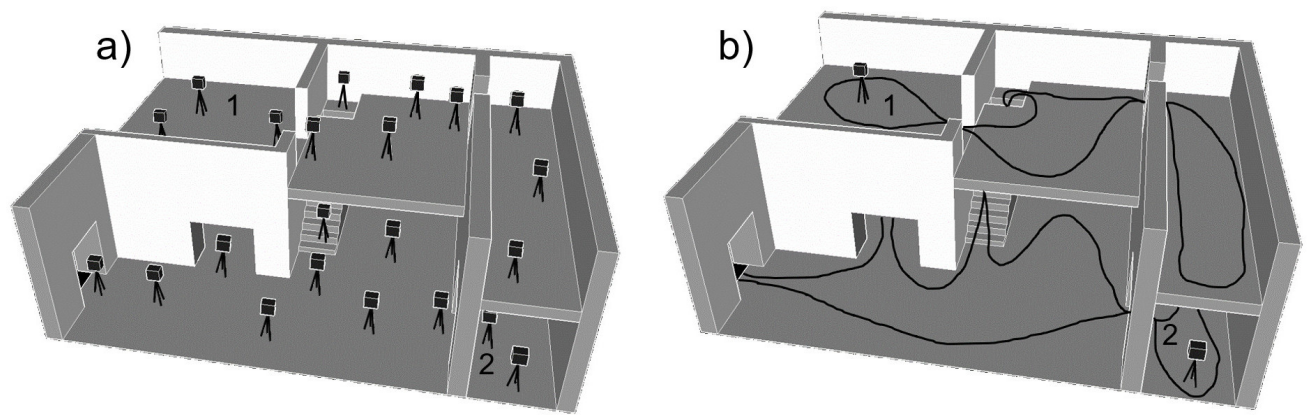

Figure 1. Illustration of registration of Rooms 1 and 2 in two cases: (a) TLS demands covering the space between Rooms 1 and 2 with TLS positions in order to register the point clouds of the two rooms together and (b) TLS with the support of a SLAM LS only requires TLS scanning positions in Rooms 1 and 2, and the area between them can be collected with a SLAM LS (the black line in the figure).

We selected applying spherical targets for the registration of the SLAM LS and TLS datasets. Alternatively, the ICP registration of point clouds would have been feasible. The SLAM point cloud covered most of the building, and for this reason, it worked as a connecting data for the non-overlapping TLS point clouds. For the point cloud registration, common targets in the spaces captured in both datasets were identified and the geometric transformations required to register the datasets were solved based on the target observations. After the registration, the TLS point clouds were located and oriented to the correct locations within the building scale framework. In Figure 2 the rough steps of the process are shown.
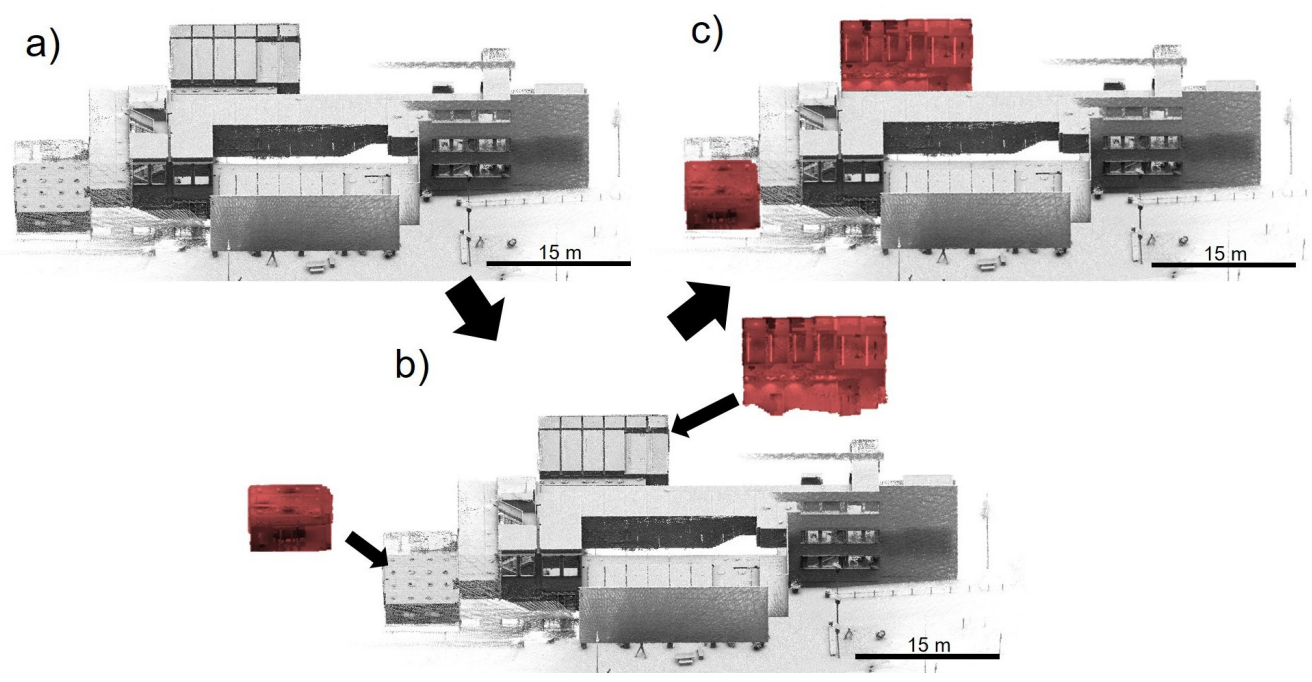

Figure 2. (a) A SLAM LS point cloud, (b) registering TLS rooms (depicted in red) to the SLAM LS point cloud and (c) the TLS rooms registered with the support of the SLAM LS point cloud.

\subsection{Case Study}

\subsubsection{Study Site}

To prove the method, we collected point clouds of a building on the Aalto University campus in Espoo, Finland. A four-story 1960s university building (designed by the architects Jaakko Kontio and Kalle Räike) was selected as a test site, featuring typical facilities found on the campus, namely lecture and meeting rooms, and corridor environments [54]. The study area includes the hallways of the two first floors of the campus building, and four rooms spread across these floors. The hallways have features such as furniture as shown in Figure 3. The overall study site is circa $900 \mathrm{~m}^{2}$ and the rooms of interest are $99.3 \mathrm{~m}^{2}$ (Room 1), $143.9 \mathrm{~m}^{2}$ (Room 2), $22.4 \mathrm{~m}^{2}$ (Room 3), and $21.5 \mathrm{~m}^{2}$ (Room 4). The heights of the 
rooms are $2.5 \mathrm{~m}$ (Room 1), $4.6 \mathrm{~m}$ (Room 2), and $3.0 \mathrm{~m}$ (Rooms 3 and 4). For the hallways, the heights are $2.5 \mathrm{~m}$, except on the second floor, in front of Room 2, where the height is $4 \mathrm{~m}$. The rooms of the building are located on every floor and mezzanine floor, such as Room 1 is at a height of $1.8 \mathrm{~m}$ from the ground floor, Room 2 is $3.25 \mathrm{~m}$ from the ground floor and Rooms 3 and 4 are $4.8 \mathrm{~m}$ from the ground floor. The dimensions of the study site are shown in Figure 4. There are six stairways in the study site; the width of the stairs is $4.21 \mathrm{~m}$ in two stairways, $1.96 \mathrm{~m}$ in three, and a single stairway is $1.80 \mathrm{~m}$ wide. The surface materials of the study site are mostly white painted concrete walls with windows. On the first floor, there is one glass wall in the hallway.

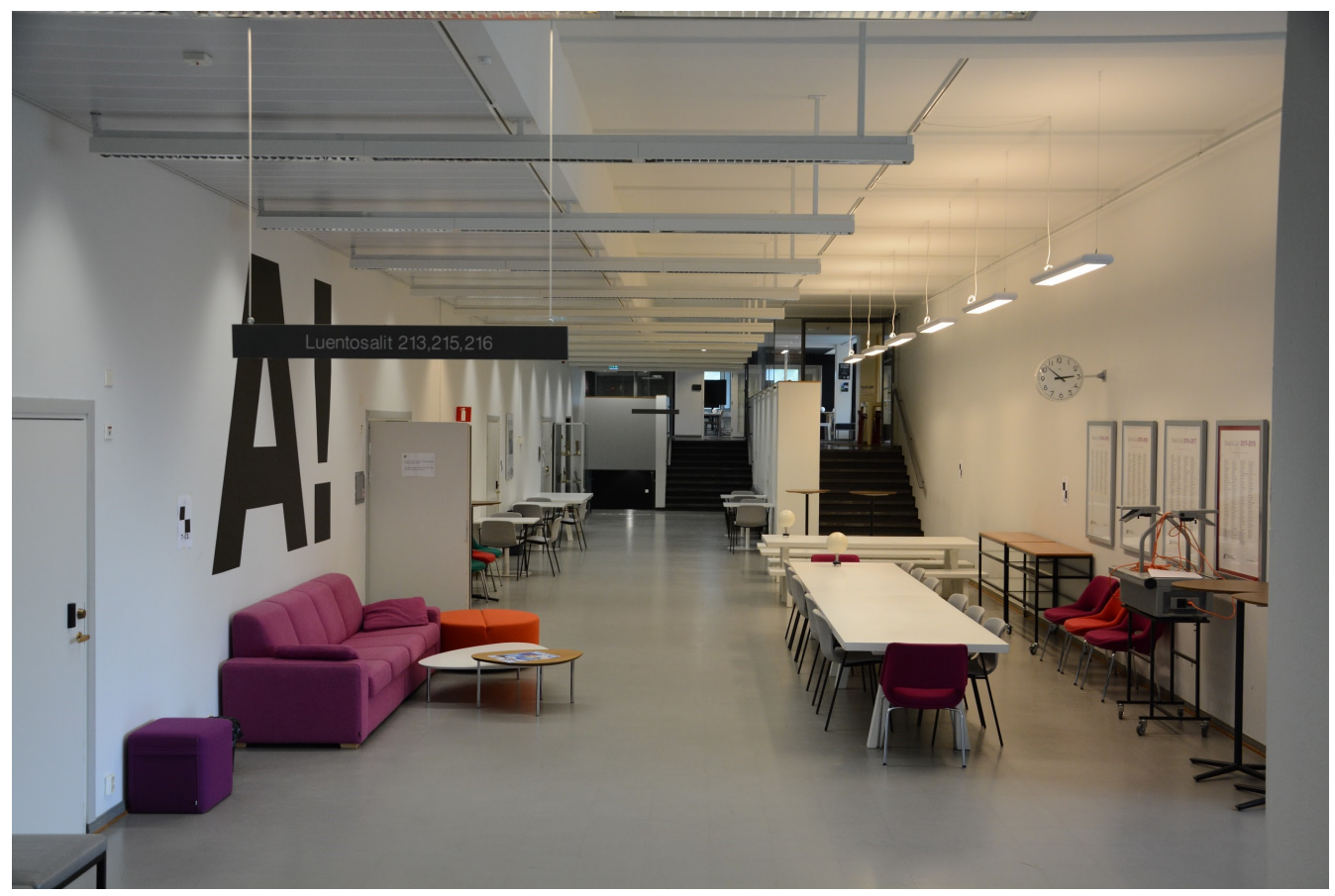

Figure 3. The hallway on the second floor.

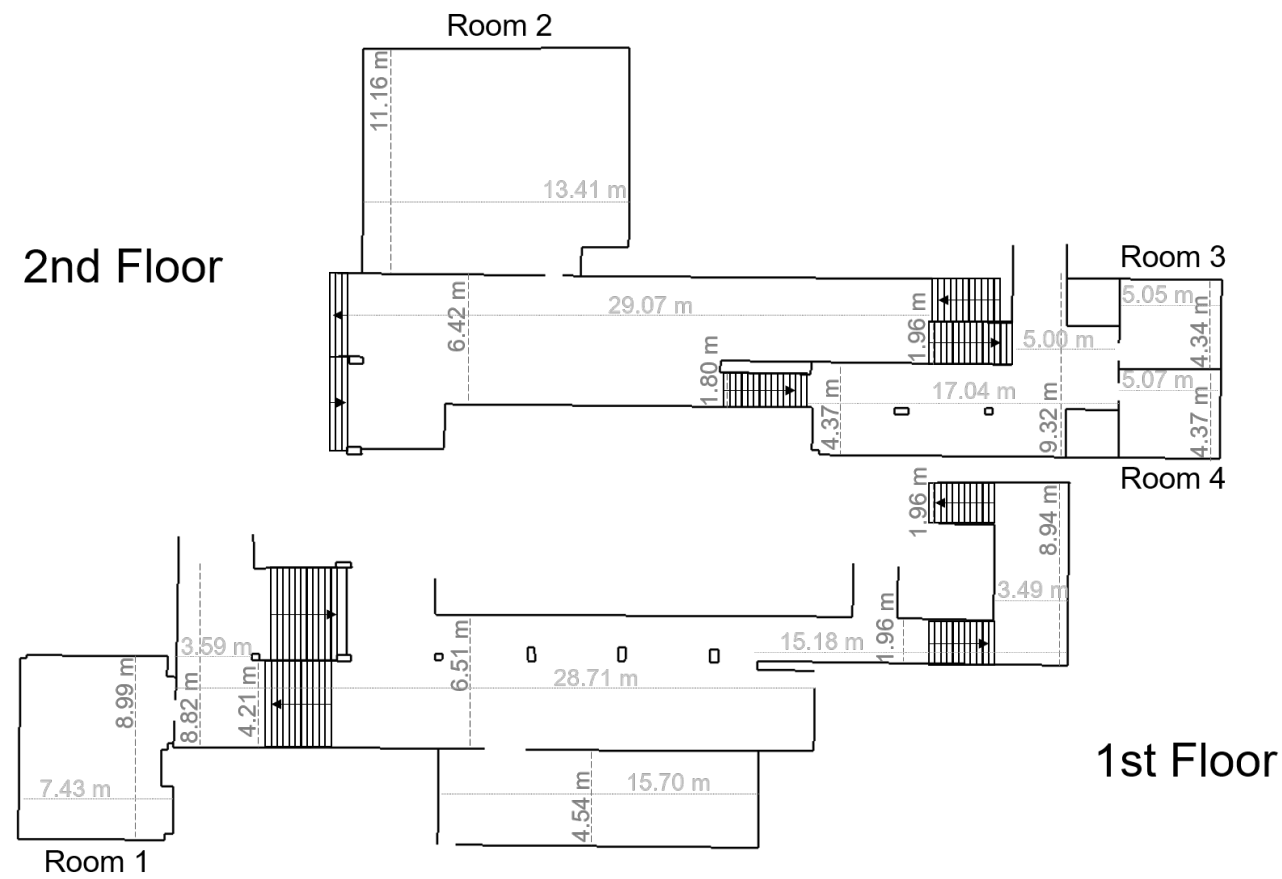

Figure 4. The floorplan of the study site with the dimensions of the rooms and hallways. 


\subsubsection{Reference Data}

The reference was collected with a Leica RTC360 with 63 scans from the whole case study area in $3.5 \mathrm{~h}$, which also sets the baseline for the data collection for the SLAM LS. The scan stations were 2-8 $\mathrm{m}$ apart. The scan parameter settings for the TLS scans were $6 \mathrm{~mm}$ point spacing at a $10 \mathrm{~m}$ distance, and scans were acquired with images from the integrated cameras. To register the individual scans, we used spheres with a $9 \mathrm{~cm}$ or $6 \mathrm{~cm}$ radius for the targets in the rooms and planar paper targets in the hallways. The registration of the scans was accomplished using the Leica REGISTER 360 software and the target spheres, paper targets, and cloud-based registration, using the same process for solving the mutual matches. The resulting point cloud registration had a $3 \mathrm{~mm}$ mean point error, a $15 \mathrm{~mm}$ maximum point error, and $62 \%$ minimum overlap.

\subsubsection{Test Data}

For the study, we collected separate TLS data from the four rooms and the SLAM LS data of the areas of interest. The TLS data of the rooms was collected with the Leica RTC360 with a $6 \mathrm{~mm}$ resolution at a distance of $10 \mathrm{~m}$. The data collection for Room 1 was executed in $11 \mathrm{~min}$, for Room 2, in $26 \mathrm{~min}$, for Room 3, in $8 \mathrm{~min}$, and for Room 4, in $5 \mathrm{~min}$. For two of the rooms, we used target spheres that had a $90 \mathrm{~mm}$ radius, and for the two other rooms the spheres had a $60 \mathrm{~mm}$ radius. These were used to register the individual scans in the Leica REGISTER 360 software. The resulting point clouds registration values are listed in Table 2.

To register these separately measured TLS rooms, we collected two SLAM LS point clouds of the areas of interest. For this, we used the ZEB Horizon SLAM LS produced by GeoSLAM. It has a relative accuracy of $10-30 \mathrm{~mm}$, the data acquisition rate is 300,000 points $/ \mathrm{s}$ and the maximum measurement distance is $100 \mathrm{~m}$ [55]. Considering the possibility to generate faster SLAM measurement with a shorter path and does it have an impact on the quality, we collected the SLAM point cloud in two different measurements by walking in the area of interest. The mapping path covered the first floor and second floor in a closed loop with loops in the rooms as shown in Figure 5. During the first mapping path, we walked around the rooms so that the path and data cover virtually the whole room. This path is later called the SLAM Cover path and it was collected in nine minutes. On the second mapping path, we only briefly visited the rooms in the proximity of the door. However, this was done in such a way that there were at least three target spheres at $1-2 \mathrm{~m}$ distance from the path with enough point density for target detection. This path is later called

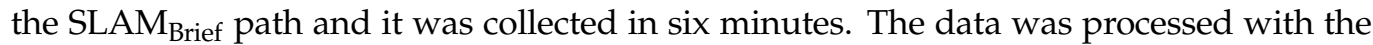
GeoSLAM Hub cloud computing service with the default settings of a voxel density 1, a maximum range $100 \mathrm{~m}$, and a closed-loop measurement, and exported in grayscale colors with computed surface normals. The characteristics of SLAM LS data in rooms 1-4 are collected in Table 3 and Figure 6.

Table 2. The registration results of the TLS of the rooms.

\begin{tabular}{ccccc}
\hline & Room 1 & Room 2 & Room 3 & Room 4 \\
\hline The radius of the target sphere (mm) & 90 & 90 & 60 & 60 \\
The number of the scans in the room & 4 & 9 & 3 & 2 \\
The mean point error (mm) & 3 & 4 & 2 & 1 \\
The maximum point error (mm) & 15 & 15 & 15 & 15 \\
Overlap (\%) & 76 & 62 & 74 & 81 \\
\hline
\end{tabular}




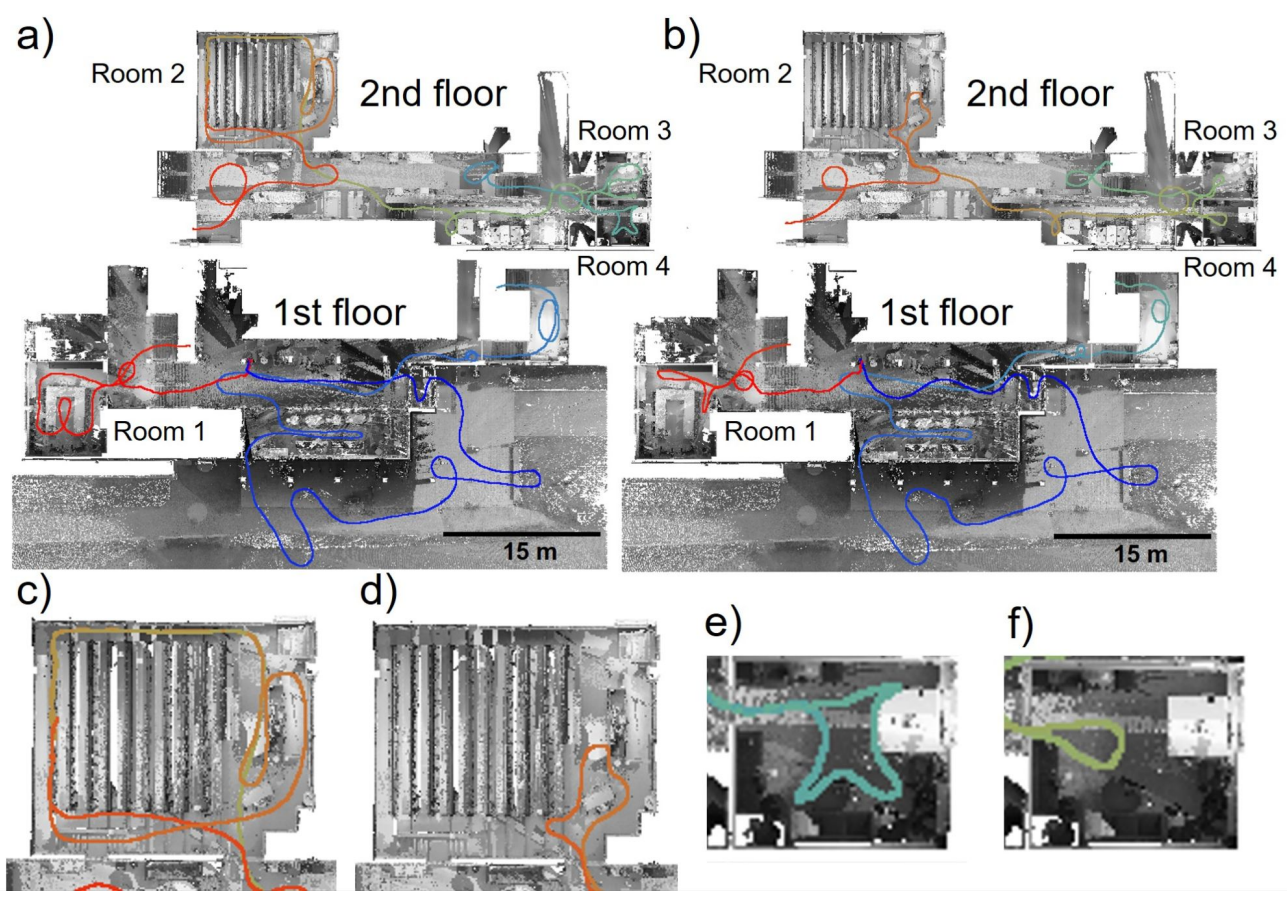

Figure 5. The walking paths of the SLAM measurements:(a) a path that covers the whole room and (b) a path that only visits the room. The path begins being depicted in red and ends as blue. The startand endpoints are located in the middle of the first floor. (c) A close-up of Room 2 with the path that covers the whole room, (d) a close up of Room 2 with the path that only visits the room, (e) a close up of Room 4 with the path that covers the whole room, and (f) a close up of Room 4 with the path that only visits the room.

Table 3. The SLAM data characteristics in rooms 1-4.

\begin{tabular}{|c|c|c|c|c|c|c|}
\hline \multirow[b]{2}{*}{ Room 1} & \multicolumn{2}{|c|}{$\begin{array}{c}\text { SLAM }_{\text {Cover }} \text { SLAM }_{\text {Brief }} \\
\text { Time (s) }\end{array}$} & \multicolumn{2}{|c|}{$\begin{array}{c}\text { SLAM }_{\text {Cover }} \text { SLAM }_{\text {Brief }} \\
\text { Trajectory Length }(\mathrm{m})\end{array}$} & \multicolumn{2}{|c|}{$\begin{array}{c}\text { SLAM }_{\text {Cover }} \text { SLAM }_{\text {Brief }} \\
\text { Number of Points (pcs) }\end{array}$} \\
\hline & 38 & 21 & 28.17 & 16.64 & 5717.508 & 2791.663 \\
\hline Room 2 & 112 & 20 & 91.72 & 14.90 & $14,768.751$ & 2950.110 \\
\hline Room 3 & 27 & 10 & 16.04 & 6.07 & 3301.177 & 1369.951 \\
\hline Room 4 & 21 & 7 & 13.36 & 5.19 & 3521.344 & 1570.171 \\
\hline
\end{tabular}
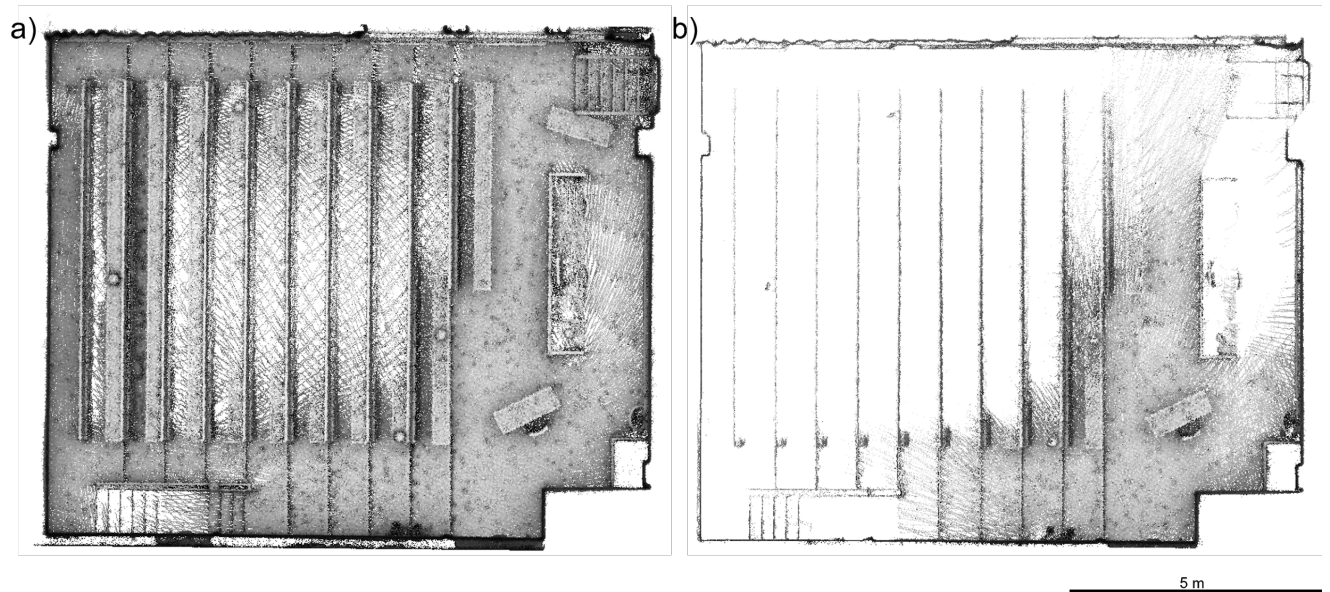

Figure 6. The data coverage in Room 2 with the SLAM LS: (a) the SLAM Cover path (b) the SLAM Brief path. 


\subsubsection{Evaluation Method}

The separately registered TLS point clouds of the rooms were aligned to the SLAM LS using CloudCompare software. At first, the SLAM LS point cloud was aligned with the TLS reference point cloud by using the sphere targets located outside, in front of the building. The target sphere is shown in the point clouds in Figure 7. This step was executed so that we can compare the reference and the SLAM LS-supported TLS room results. Then, all the rooms were aligned to the SLAM LS point clouds with the sphere targets located in the rooms. After this alignment, we merged the data from the rooms into one point cloud even though there was no TLS overlap between them. The process is represented in Figure 8. For the analyzing purposes of the room locations, TLS rooms are not merged with the rest of the SLAM data.

a)

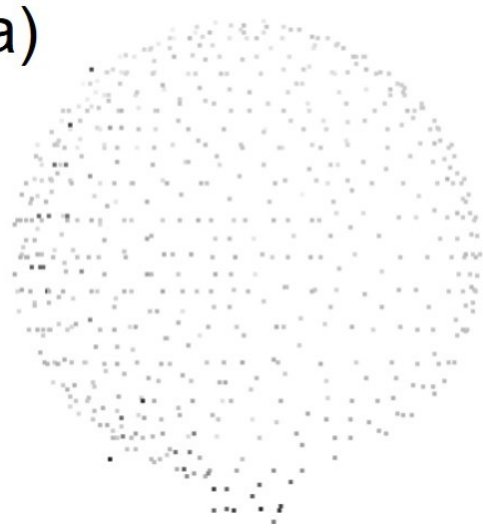

b)

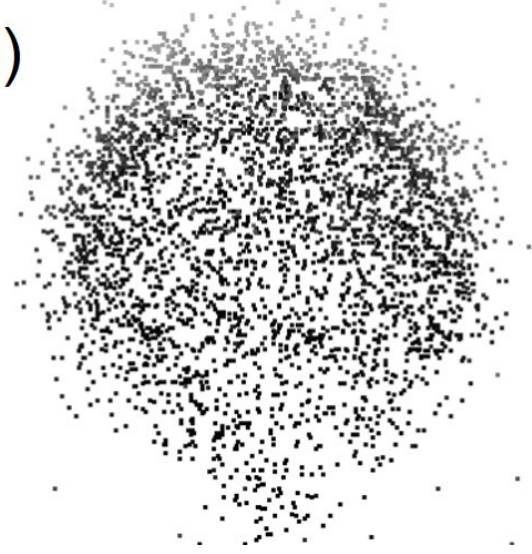

Figure 7. Comparison of a target sphere (radius $90 \mathrm{~mm}$ ) as found in the point clouds. (a) A target sphere in TLS point cloud (b) in SLAM LS point cloud.

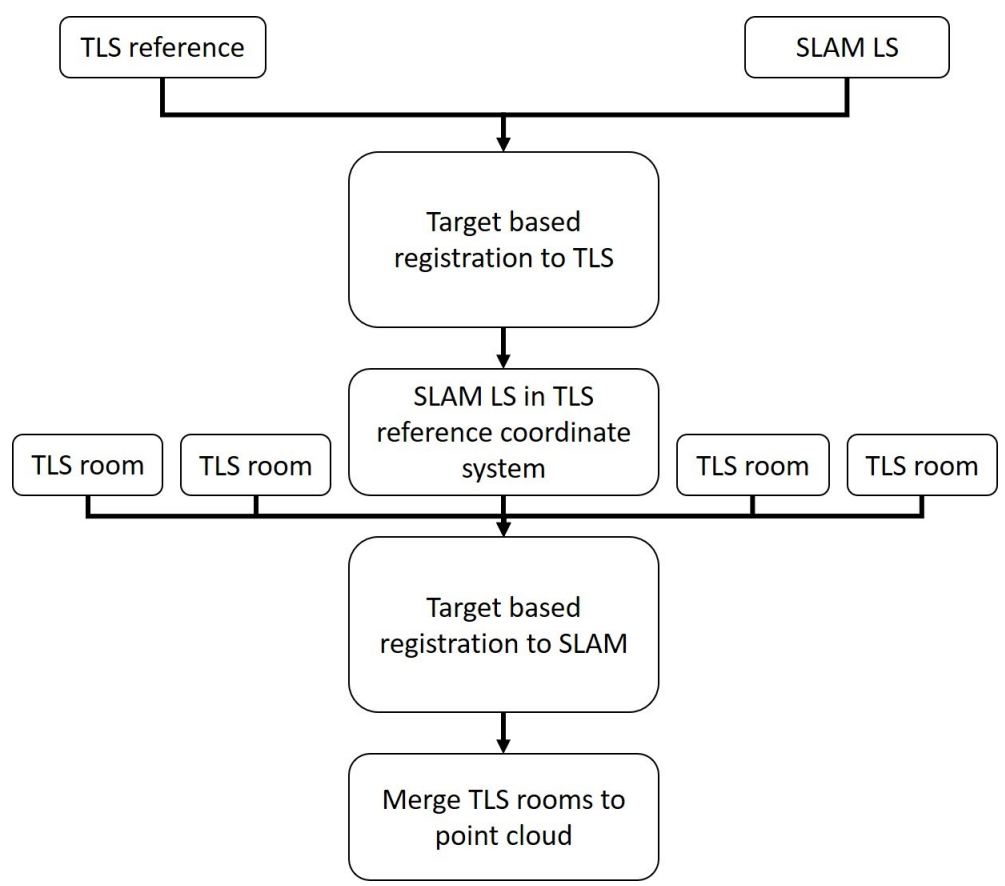

Figure 8. The process of registering the TLS point clouds of the rooms with the support of the SLAM LS point cloud.

To analyze the accuracy of the SLAM LS-supported non-overlapping TLS point clouds, we compare the SLAM-supported TLS room locations (TLS room) with the reference point

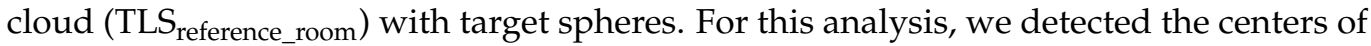


the target spheres from the reference $\left(\mathrm{TLS}_{\text {reference_room }}\right)$ as well as from the $\mathrm{TLS}_{\text {room }}$ in the rooms (1-4). There were four target spheres in rooms 1, 3, 4, and six in room 2 that were used in the analysis. These center points of the target spheres were compared with the statistical calculation of 3D Euclidean distance with the equation;

$$
3 \text { Ddistance }=\sqrt{\left(x_{2}-x_{1}\right)^{2}+\left(y_{2}-y_{1}\right)^{2}+\left(z_{2}-z_{1}\right)^{2}}
$$

The comparisons were done from individual rooms and all the target spheres of the rooms. The process is represented in Figure 9.

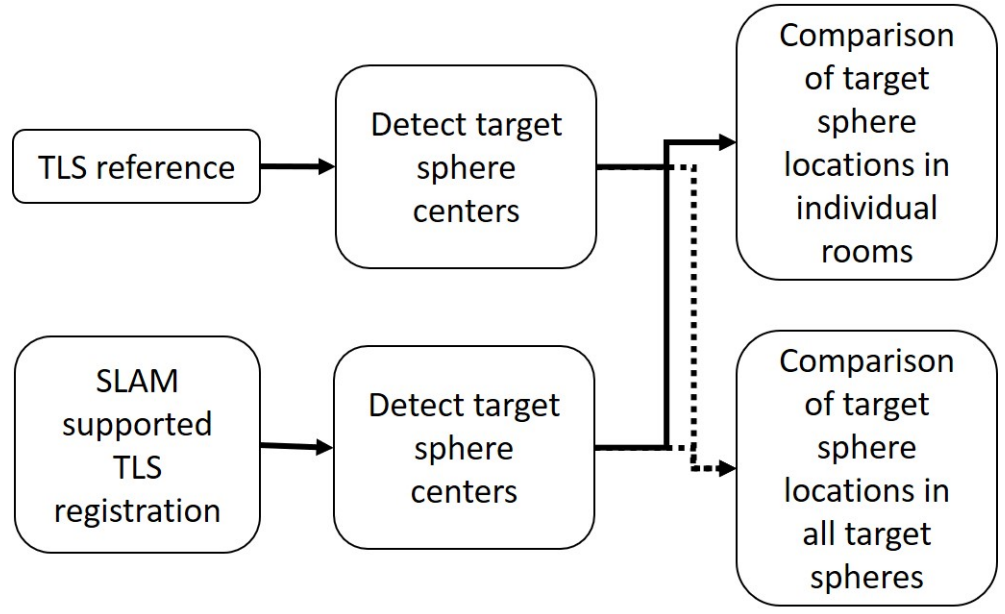

Figure 9. The process of the target sphere comparison between the SLAM registered TLS room $_{\text {point }}$ cloud and reference point clouds $\left(\mathrm{TLS}_{\text {reference_room }}\right)$ for individual rooms and merged rooms.

\section{Results}

\subsection{Registration}

The results of the alignment are listed in Table 4. The errors include the errors of individual target spheres as well as the root mean square errors (RMSEs) between the reference point cloud and the SLAM LS point cloud based on the target spheres that are located outside the building. The alignment between the reference and SLAM LS point clouds is $14.84 \mathrm{~mm}$ in the case of the SLAM Cover $_{\text {path and } 11.99 \mathrm{~mm} \text { for the SLAM }}$ Brief path. In addition, Table 5 presents the individual target errors as well as the combined RMSE of all target spheres in a room. Due to the noise of the SLAM LS point cloud, the maximum target sphere errors differ, ranging from $9.62 \mathrm{~mm}$ to $28.49 \mathrm{~mm}$.

Table 4. The errors of Target Sphere of the SLAM LS alignment to the reference and the combined root mean square error (RMSE) of all Target Spheres. All four used Target Spheres were located outside, in front of the building.

\begin{tabular}{|c|c|c|}
\hline $\begin{array}{c}\text { The Path } \\
\text { Name }\end{array}$ & The Error & $\begin{array}{l}\text { SLAM to TLS } \\
\text { Reference }\end{array}$ \\
\hline SLAM $_{\text {Cover }}$ & The errors of individual Target Spheres outside the building (mm) & $\begin{array}{l}11.91 \\
15.76 \\
13.99 \\
17.69\end{array}$ \\
\hline SLAM $_{\text {Brief }}$ & $\begin{array}{l}\text { Combined RMSE of all outside Target Spheres (mm) } \\
\text { The errors of individual Target Spheres outside the building }(\mathrm{mm})\end{array}$ & $\begin{array}{c}14.84 \\
16.45 \\
7.52 \\
10.37 \\
11.83\end{array}$ \\
\hline & Combined RMSE of all outside Target Spheres (mm) & 11.99 \\
\hline
\end{tabular}


Table 5. The errors of Target Sphere of the TLS rooms' registration with SLAM LS support and the combined root mean square error (RMSE) of all Target Spheres. For the SLAM Cover $_{\text {path, we used }}$ three target spheres in Rooms 1,3, and 4; and for the SLAM Brief path, we used three target spheres in Rooms 1 and 2. Other alignments were used for four target spheres.

\begin{tabular}{|c|c|c|c|c|c|}
\hline $\begin{array}{l}\text { The Path } \\
\text { Name }\end{array}$ & The Error & $\begin{array}{c}\text { TLS } \\
\text { Room } 1 \\
\text { to SLAM }\end{array}$ & $\begin{array}{c}\text { TLS } \\
\text { Room } 2 \\
\text { to SLAM }\end{array}$ & $\begin{array}{c}\text { TLS } \\
\text { Room } 3 \\
\text { to SLAM }\end{array}$ & $\begin{array}{c}\text { TLS } \\
\text { Room } 4 \\
\text { to SLAM }\end{array}$ \\
\hline SLAM $_{\text {Cover }}$ & $\begin{array}{l}\text { The errors of individ- } \\
\text { ual Target Spheres in } \\
\text { a room }(\mathrm{mm})\end{array}$ & $\begin{array}{l}6.92 \\
6.74 \\
7.18\end{array}$ & $\begin{array}{l}8.41 \\
9.21 \\
9.62 \\
8.37 \\
\end{array}$ & $\begin{array}{l}9.38 \\
5.03 \\
8.06\end{array}$ & $\begin{array}{l}8.19 \\
8.50 \\
9.60\end{array}$ \\
\hline \multirow{3}{*}{ SLAM $_{\text {Brief }}$} & $\begin{array}{l}\text { Combined RMSE of all } \\
\text { room Target Spheres (mm) }\end{array}$ & 7.03 & 8.86 & 7.31 & 8.85 \\
\hline & $\begin{array}{l}\text { The errors of individ- } \\
\text { ual Target Spheres in } \\
\text { a room }(\mathrm{mm})\end{array}$ & $\begin{array}{l}6.69 \\
2.79 \\
5.00\end{array}$ & $\begin{array}{l}11.67 \\
13.62 \\
23.00\end{array}$ & $\begin{array}{c}22.82 \\
13.07 \\
28.49 \\
8.45\end{array}$ & $\begin{array}{c}16.06 \\
18.69 \\
9.75 \\
18.82 \\
\end{array}$ \\
\hline & $\begin{array}{l}\text { Combined RMSE of all } \\
\text { room Target Spheres (mm) }\end{array}$ & 5.08 & 16.84 & 19.84 & 16.07 \\
\hline
\end{tabular}

\subsection{The Accuracy Assessment of the Room Point Cloud Locations}

The results of the target sphere locations comparison between SLAM registered (TLS $\left.{ }_{\text {room }}\right)$ point cloud and reference $\left(\mathrm{TLS}_{\text {reference_room }}\right)$ are listed in Table 6. The mean 3D distance results for all the target spheres is $39.96 \mathrm{~mm}$ for the $\mathrm{SLAM}_{\text {Cover }}$ path and $34.94 \mathrm{~mm}$ for the SLAM Brief path. For the individual rooms, the largest differences between

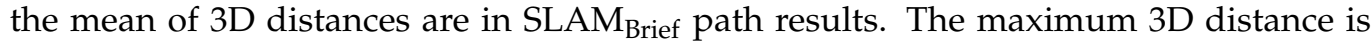
$51.20 \mathrm{~mm}$ and the minimum is $18.25 \mathrm{~mm}$ of the room.

Table 6. The results for the 3D distance between target spheres in $\mathrm{TLS}_{\text {room }}$ and reference $\left(\mathrm{TLS}_{\text {reference_room }}\right)$. The path name tells that the TLS room point cloud is registered either with the point cloud of SLAM ${ }_{\text {Cover }}$ or SLAM Brief $_{\text {trajectory. }}$

\begin{tabular}{ccc}
\hline The Path Name & Space & $\begin{array}{c}\text { Mean of the 3D Distance of } \\
\text { Target Spheres } \mathbf{( m m})\end{array}$ \\
\hline & Room 1 & 31.67 \\
SLAM $_{\text {Cover }}$ & Room 2 & 37.11 \\
& Room 3 & 49.87 \\
& Room 4 & 42.60 \\
& All rooms & 39.96 \\
SLAM $_{\text {Brief }}$ & Room 1 & 41.54 \\
& Room 2 & 51.20 \\
& Room 3 & 20.66 \\
& Room 4 & 18.25 \\
& All rooms & 34.94 \\
\hline
\end{tabular}

\section{Discussion}

Our experiment showed that the non-overlapping TLS point clouds of the rooms can be located with SLAM support (TLS Trom ) to an accuracy of $39.96 \mathrm{~mm}$ for a mapping

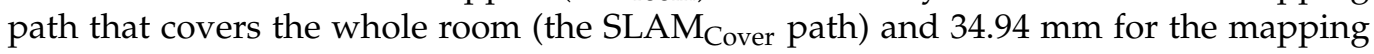
path that only briefly visits the room in the proximity of the door (the SLAM Brief path) in the target sphere comparison. (Table 6). The results of the target sphere analysis are very close in both paths. The results indicate that SLAM LS-supported non-overlapping TLS point cloud registration is possible with reasonable accuracy. Especially when the result accuracy is compared to the laboriousness of the TLS measurements. With TLS we need to collect data from the rooms and from the hallways between the rooms that will 
add remarkably collection time. During this study, we have proven that data collection time can be minimized with SLAM LS measurements and the accuracy of the TLS room locations is reasonable. The improvement of data collection time was $72 \%$ compared to TLS measurements. For this reason, this approach provides a comprehensive point cloud of a building with the required accuracy of the application, for example BIM, with less labor involved in creating extra TLS stations to connect non-overlapping or weakly overlapping point clouds in complex geometries/building environments.

The alignment accuracy of the SLAM point cloud to the reference was $14.84 \mathrm{~mm}$ for

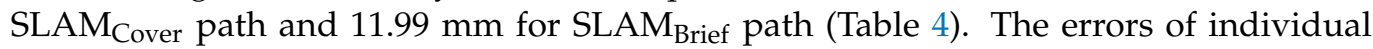
targets were 11.91-17.69 for SLAM Cover $_{\text {path and 7.52-16.45 for SLAM }}$ Brief path. Both of these paths align well at the $10 \mathrm{~mm}$ level considering the relative accuracy of the SLAM system to be $10-30 \mathrm{~mm}$. The TLS measured rooms could be registered to the SLAM point cloud with a best accuracy of $5 \mathrm{~mm}$, while the worst case provided $20 \mathrm{~mm}$ when individual target sphere errors was 3-28 $\mathrm{mm}$ (Table 5). The TLS rooms registered to the SLAM $\mathrm{Mover}_{\mathrm{C}}$ path between 7.03-8.86 mm accuracy. The corresponding values for SLAM Brief $_{\text {path }}$ were higher in every room except Room 1 . The accuracy was 16.07-19.84 mm for Rooms 2, 3, 4, and $5.08 \mathrm{~mm}$ for Room 1. The registration of TLS rooms to SLAM point cloud functions as expected in Rooms 2, 3, and 4 with SLAM Brief path. The SLAM Brief had fewer data and the registration accuracy became weaker. However, in Room 1 registration does not provide coherent result. The difference could be due to the SLAM path. The SLAM Brief path may not detect enough features during the beginning of the measurement leading to small misalignment in the SLAM LS point cloud. This small misalignment has probably happened after Room 1 because the registration value of Room 1 is very close to those of the SLAM ${ }_{\text {Cover }}$ path. After Room 1 the misalignment spread through the path and led to larger values for the registrations of Rooms 2, 3, and 4.

Even though there were differences in the TLS room registrations between the SLAM paths (Table 5) it has only a very small impact on the target sphere comparison of all rooms (Table 6). Based on these results SLAM Brief path has a small impact on the results when we

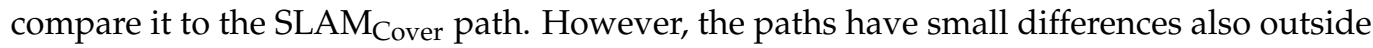
the rooms, which may have more impact on the SLAM LS point cloud than the changes in the paths in the rooms. Before the possible misalignment of the SLAM ${ }_{\text {Brief }}$ path, the 3D distances of the target spheres are on the same scale as with the SLAM Cover $_{\text {path. The values }}$ of the 3D distances differ only by circa $15 \mathrm{~mm}$ in SLAM Cover $_{\text {path }}(31.67-49.87 \mathrm{~mm})$ and the value of Room 1 of SLAM Brief path is also on the same scale with a value of $41.54 \mathrm{~mm}$. After the misalignment of the SLAM ${ }_{\text {Brief }}$ path, the values differ more than $18.25-51.20 \mathrm{~mm}$

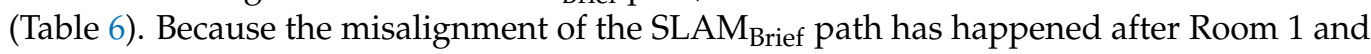
on the other hand before Room 2 (Tables 5 and 6) it appears that the overall path has more impact on the SLAM-supported non-overlapping TLS room registration than the visiting time of the rooms.

In addition, there is a possibility that the size of the room has an impact on the TLS room location in the SLAM LS supported registration. There is a difference between larger and smaller rooms in both paths. In the SLAM Cover $_{\text {path, the error difference is circa } 10 \mathrm{~mm}}$ larger in smaller rooms (under $25 \mathrm{~m}^{2}$ ) than in bigger rooms (over $90 \mathrm{~m}^{2}$ ), and circa $20 \mathrm{~mm}$ larger in bigger rooms than in smaller rooms with SLAM Brief $_{\text {path (Table 6). It appears }}$ that the smaller rooms require less data with SLAM LS than bigger rooms for an accurate TLS room registration and the opposite for the bigger rooms. Based on these results the combination of the SLAM LS paths would be best. The size of the rooms should affect the SLAM LS path in the rooms. In bigger rooms, we should use SLAM Cover $_{\text {path, and in }}$

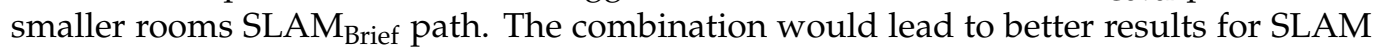
LS-supported non-overlapping TLS room registration. Based on the results, SLAM LS is more affected by the overall path and room sizes than the small difference between SLAM $_{\text {Cover }}$ and SLAM Brief $_{\text {paths within the rooms. }}$

The SLAM LS has some disadvantages. These have been listed in many of the earlier studies experimenting with GeoSLAM LSs. SLAM has problems when the environment is 
elongated and narrow or exceedingly large (in terms of scanner range performance) with a lack of features, such as furniture or other objects that are suitable as geometric targets for robust matching, or an open space [56,57]. Lidar-based SLAM requires features at small intervals in every environment and the measurements demand paths with closed loops to improve the internal geometric integrity [51]. In most indoor environments, there are naturally a sufficient number of geometric features at sufficiently short intervals/distances, while environments with insufficient/disadvantageous geometric properties are a minority. However, in such cases it is possible to add features to the obvious areas with disadvantageous characteristics in order to overcome the SLAM deficiencies in environments, such as narrow corridors, for example, by adding furniture or other objects, or opening doors to provide additional surfaces with geometric variance in order to help the SLAM and other data registration. Besides this, the ranging performance of the particular sensor restricts perception [39,58]. Most of the indoor environments have features within the $30 \mathrm{~m}$ range, which is typically even well suited for the short-sighted SLAM LSs. The tested GeoSLAM Zeb Horizon equipped with a Velodyne VLP-16 exhibits a relatively long-range performance that is suitable for outdoor and even UAV applications [59].

The spatial error of any particular SLAM solution will cumulate with the increased time spent on the data collection [60]. This needs to be considered when assessing the value of the proposed methods. For a GeoSLAM LS, the maximum data collection time is $30 \mathrm{~min}$, and during that time, the error will be contained provided that the requirements for the system operation are considered. Because of these listed disadvantages, the operations require reasonable planning before mapping the environment [25]. Furthermore, TLS scanning requires planning, and in comparison with that, planning for SLAM LS mapping is easier. SLAM LS point cloud collection does not take substantial time. For this reason, with a SLAM LS, it is possible to collect data from the desired site twice in order to make sure that the system works correctly in the environment.

The point density of SLAM LS point clouds depends on measurement distances from the scanner to the features and mapping speed [57]. The data is especially noisy in areas where the walking speed is slower $[39,41,57]$. Because of noise, it is difficult to recognize small objects that are under $3 \mathrm{~cm}$ in size or the placements of windows [24,41]. Despite this fact, it was possible to reach a sufficient point density in order to locate non-overlapping TLS point clouds in an indoor environment with the accuracy of $39.96 \mathrm{~mm}$ for the mapping

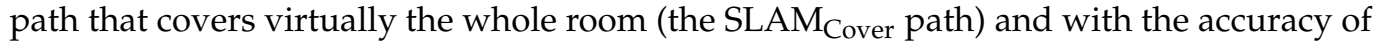
$34.94 \mathrm{~mm}$ for the mapping path that only briefly visited the room in the proximity of the

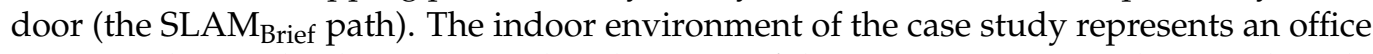
interior. The results demonstrate that the noise of the SLAM LS system does not hugely affect the registration and 3D mapping accuracy of the TLS point clouds.

The georeferencing of the SLAM LS point cloud requires control points. However, not all the GeoSLAM systems can use plane targets [22,61]. The introduced method will not remove the need for control. The targets need to be chosen with consideration of the sensor capacity. However, it is also possible to use the method with cloud-based registration to another georeferenced point cloud.

The represented method of TLS 3D mapping with SLAM support is faster than TLS. The data acquisition time is circa $1 \mathrm{~h}$ including the measurements for the individual TLS rooms and using SLAM LS for the hallways. For the same area, the TLS reference is collected in $3.5 \mathrm{~h}$. However, the used TLS device Leica RTC360 can also use visual odometry to improve the data collection time; it will not be as fast as the represented combination of SLAM and TLS. As an alternative method, it would be possible to use other sensors, such as a depth camera, in the case of using SLAM LS. However, Chen et al. [27] studied that the depth camera, as the Matterport 3D camera, has weaker accuracy and lower point density than tested SLAM methods.

This method could be expanded to integrate the indoor environments into the outside world. In this case, the SLAM data also needs to be collected outside the building, as we did. The outdoor SLAM point cloud needs to cover enough features that it is possible to 
integrate it with existing outdoor point clouds—such as aerial, mobile laser scanner point clouds - or other reference data. The SLAM point cloud can contain both outdoor and indoor measurements because SLAM enables data collection in complex environments with the opportunity to move easily from one environment to another [40,60]. In this case, the registration of the SLAM point cloud with the existing outdoor point cloud would be the first step in the registration. The rest of the steps would be the same as without the outdoor integration. The SLAM LS point cloud collection is faster than TLS and the point cloud can be easily expanded to cover areas that are easier to georeference, such as the lower floors of high buildings.

\section{Conclusions}

In this paper, we illustrated the potential use of SLAM LS data for supporting the building-scale registration of non-overlapping TLS point clouds in order to reconstruct comprehensive building floor/3D maps. The presented strategy improves efficiency since it allows TLS data to only be collected from those parts of the building that require such accuracy. The rest of the building can be measured with SLAM LS accuracy, which data provide a common frame for registering all new data for facility management purposes.

In our test case, we found that 3D mapping of non-overlapping TLS data covering individual rooms was possible with $18-51 \mathrm{~mm}$ based on accuracy assessment with target sphere reference. Based on our case study, the overall path has more impact on the SLAM-supported non-overlapping TLS room registration than the visiting time of the rooms. In addition, the method saves time. Our test was performed in a normal indoor office environment that included a lot of features supporting the SLAM LS solution. However, one must remember that using a SLAM LS is prone to having larger orientation problems if not enough suitable features are available. Therefore, it is recommended that the area in focus is carefully examined beforehand and supporting features are placed into the environment if needed.

Author Contributions: A.K. (Aino Keitaanniemi) acted as the sole first author, collected the SLAM LS data and processed the data to obtain the results and wrote the majority of the article. A.K. (Antero Kukko), M.T.V. and T.R. planned and carried out the TLS data measurements. J.-P.V., P.R., A.K. (Antero Kukko) and M.T.V. acted as senior authors. A.K. (Aino Keitaanniemi), J.-P.V. and M.T.V. made the experimental plan, provided basic concepts for data processing, and complemented in writing of the paper. P.R. and A.K. (Antero Kukko) provided insights throughout the paper, and improved the manuscript. All authors have read and agreed to the published version of the manuscript.

Funding: This research was funded by Aalto University School of Engineering Tenure track (Digital Photogrammetry) funding, the Academy of Finland the Strategic Research Council projects, "CompetenceBased Growth Through Integrated Disruptive Technologies of 3D Digitalization, Robotics, Geospatial Information, and Image Processing/Computing-Point Cloud Ecosystem" (No. 293389, 314312), Academy of Finland project “Quality4Roads" (No. 323783), project Profi5 “Autonomous systems" (No. 326246), the European Social Fund (S21997) and the City of Helsinki Innovation fund.

Institutional Review Board Statement: Not applicable.

Informed Consent Statement: Not applicable.

Conflicts of Interest: The authors declare no conflict of interest. The funders had no role in the design of the study; in the collection, analyses, or interpretation of data; in the writing of the manuscript, or in the decision to publish the results.

\section{References}

1. Georgopoulos, A.; Stathopoulou, E.K. Data Acquisition for 3D Geometric Recording: State of the Art and Recent Innovations. In Heritage and Archaeology in the Digital Age: Acquisition, Curation, and Dissemination of Spatial Cultural Heritage Data; Vincent, M.L., López-Menchero Bendicho, V.M., Ioannides, M., Levy, T.E., Eds.; Quantitative Methods in the Humanities and Social Sciences; Springer International Publishing: Cham, Switzerland, 2017; pp. 1-26. [CrossRef]

2. Büyüksalih, G.; Kan, T.; Özkan, G.E.; Meriç, M.; Isın, L.; Kersten, T.P. Preserving the Knowledge of the Past Through Virtual Visits: From 3D Laser Scanning to Virtual Reality Visualisation at the Istanbul Çatalca İnceğiz Caves. PFG J. Photogramm. Remote Sens. Geoinf. Sci. 2020, 88, 133-146. [CrossRef] 
3. Nowak, R.; Orłowicz, R.; Rutkowski, R. Use of TLS (LiDAR) for Building Diagnostics with the Example of a Historic Building in Karlino. Buildings 2020, 10, 24. [CrossRef]

4. Liu, J.; Xu, D.; Hyyppä, J.; Liang, Y. A Survey of Applications with Combined BIM and 3D Laser Scanning in the Life Cycle of Buildings. IEEE J. Sel. Top. Appl. Earth Obs. Remote Sens. 2021, 14, 5627-5637. [CrossRef]

5. Hichri, N.; Stefani, C.; Luca, L.; Véron, P. Review Of The “As-built BIM" Approaches. ISPRS Int. Arch. Photogramm. Remote Sens. Spat. Inf. Sci. 2013, XL-5/W1, 107-112. [CrossRef]

6. $\quad$ Sanhudo, L.; Ramos, N.M.M.; Martins, J.P.; Almeida, R.M.S.F.; Barreira, E.; Simões, M.L.; Cardoso, V. A framework for in-situ geometric data acquisition using laser scanning for BIM modelling. J. Build. Eng. 2020, 28, 101073. [CrossRef]

7. Pica, D.; Abanda, F. Emerging BIM-3D-Laser Scanning Integration in Construction Practice. In Proceedings of the CITC Global-Construction in the 21st Century, London, UK, 9-11 September 2019

8. Díaz-Vilariño, L.; Khoshelham, K.; Martínez-Sánchez, J.; Arias, P. 3D Modeling of Building Indoor Spaces and Closed Doors from Imagery and Point Clouds. Sensors 2015, 15, 3491-3512. [CrossRef]

9. Jia, F.; Lichti, D.D. A Model-Based Design System for Terrestrial Laser Scanning Networks in Complex Sites. Remote Sens. 2019, 11, 1749. [CrossRef]

10. Pérez Ramos, A.; Robleda Prieto, G. 3D Virtualization by Close Range Photogrammetry Indoor Gothic Church Apses. The Case Study of Church of San Francisco in Betanzos (la CORUÑA, Spain). ISPRS Int. Arch. Photogramm. Remote Sens. Spat. Inf. Sci. 2015, XL-5/W4, 201-206. [CrossRef]

11. Hartono, J.R.; Oei, F.J. A Proposal of image-based measurement instead of laser-based measurement for indoor application. IOP Conf. Ser. Mater. Sci. Eng. 2020, 1007, 012026. [CrossRef]

12. Kalantari, M.; Nechifor, M. Accuracy and utility of the Structure Sensor for collecting 3D indoor information. Geo-Spat. Inf. Sci. 2016, 19, 202-209. [CrossRef]

13. Pintore, G.; Mura, C.; Ganovelli, F.; Fuentes-Perez, L.; Pajarola, R.; Gobbetti, E. State-of-the-art in Automatic 3D Reconstruction of Structured Indoor Environments. Comput. Graph. Forum 2020, 39, 667-699. [CrossRef]

14. Maboudi, M.; Bánhidi, D.; Gerke, M. Evaluation of Indoor Mobile Mapping Systems. In Proceedings of the GFaI Workshop 3D North East 2017 (20th Application-oriented Workshop on Measuring, Modeling, Processing and Analysis of 3D-Data), Berlin, Germany, 7-8 December 2017.

15. Salgues, H.; Macher, H.; Landes, T. Evaluation of Mobile Mapping Systems For Indoor Surveys. Int. Arch. Photogramm. Remote Sens. Spat. Inf. Sci. 2020, 44, 119-125. [CrossRef]

16. Bassier, M.; Yousefzadeh, M.; Van Genechten, B. Evaluation of Data Acquisition Techniques and Workflows for Scan to BIM; Geo Bussiness: London, UK, 2015.

17. Kersten, T.P.; Mechelke, K.; Lindstaedt, M.; Sternberg, H. Methods for Geometric Accuracy Investigations of Terrestrial Laser Scanning Systems. Photogramm. Fernerkund. Geoinf. 2009, 2009, 301-315. [CrossRef]

18. Ingman, M.; Virtanen, J.P.; Vaaja, M.T.; Hyyppä, H. A Comparison of Low-Cost Sensor Systems in Automatic Cloud-Based Indoor 3D Modeling. Remote Sens. 2020, 12, 2624. [CrossRef]

19. Cantoni, S.; Vassena, G. Fast Indoor Mapping To Feed An Indoor Db For Building And Facility Management. In Proceedings of the 8th International Workshop 3D-ARCH "3D Virtual Reconstruction and Visualization of Complex Architectures" on International Archives of the Photogrammetry, Remote Sensing and Spatial Information Sciences, Bergamo, Italy, 6-8 February 2019; Volume XLII-2-W9, pp. 213-217. [CrossRef]

20. Hullo, J.F.; Grussenmeyer, P.; Landes, T.; Thibault, G. Georeferencing Of Tls Data For Industrial Indoor Complex Scenes: Beyond Current Solutions. In Proceedings of the ISPRS Calgary 2011 Workshop on International Archives of the Photogrammetry, Remote Sensing and Spatial Information Sciences, Calgary, Canada, 29-31 August 2011; Volume XXXVIII-5-W12, pp. 185-190. [CrossRef]

21. Soudarissanane, S.; Lindenbergh, R. Optimizing terrestrial laser scanning measurement set-up. ISPRS Int. Arch. Photogramm. Remote Sens. Spat. Inf. Sci. 2012, XXXVIII-5/W12. [CrossRef]

22. Tucci, G.; Visintini, D.; Bonora, V.; Parisi, E.I. Examination of Indoor Mobile Mapping Systems in a Diversified Internal/External Test Field. Appl. Sci. 2018, 8, 401. [CrossRef]

23. Tang, J.; Wen, J.; Qian, C. A Distributed Indoor Mapping Method Based on Control-Network-Aided SLAM: Scheme and Analysis. Appl. Sci. 2020, 10, 2420. [CrossRef]

24. Sirmacek, B.; Shen, Y.; Lindenbergh, R.; Zlatanova, S.; Diakite, A. Comparison Of Zeb1 And Leica C10 Indoor Laser Scanning Point Clouds. ISPRS Ann. Photogramm. Remote Sens. Spatial Inf. Sci. 2016, III-1, 143-149 [CrossRef]

25. Chiabrando, F.; Della Coletta, C.; Sammartano, G.; Spanò, A.; Spreafico, A. “Torino 1911” Project: A Contribution Of A SLAMbased Survey To Extensive 3D Heritage Modeling. Int. Arch. Photogramm. Remote Sens. Spat. Inf. Sci. 2018, XLII-2, $225-234$. [CrossRef]

26. Di Filippo, A.; Sánchez-Aparicio, L.J.; Barba, S.; Martín-Jiménez, J.A.; Mora, R.; González Aguilera, D. Use of a Wearable Mobile Laser System in Seamless Indoor 3D Mapping of a Complex Historical Site. Remote Sens. 2018, 10, 1897. [CrossRef]

27. Chen, Y.; Tang, J.; Jiang, C.; Zhu, L.; Lehtomäki, M.; Kaartinen, H.; Kaijaluoto, R.; Wang, Y.; Hyyppä, J.; Hyyppä, H.; et al. The Accuracy Comparison of Three Simultaneous Localization and Mapping (SLAM)-Based Indoor Mapping Technologies. Sensors 2018, 18, 3228. [CrossRef] 
28. Lehtola, V.V.; Kaartinen, H.; Nüchter, A.; Kaijaluoto, R.; Kukko, A.; Litkey, P.; Honkavaara, E.; Rosnell, T.; Vaaja, M.T.; Virtanen, J.P.; et al. Comparison of the Selected State-Of-The-Art 3D Indoor Scanning and Point Cloud Generation Methods. Remote Sens. 2017, 9, 796. [CrossRef]

29. Sepasgozar, S.M.E.; Davis, S. Construction Technology Adoption Cube: An Investigation on Process, Factors, Barriers, Drivers and Decision Makers Using NVivo and AHP Analysis. Buildings 2018, 8, 74. [CrossRef]

30. Allmon, E.; Haas, C.T.; Borcherding, J.D.; Goodrum, P.M. U.S. Construction Labor Productivity Trends, 1970-1998. J. Constr. Eng. Manag. 2000, 126, 97-104. [CrossRef]

31. Lu, C.X.; Rosa, S.; Zhao, P.; Wang, B.; Chen, C.; Stankovic, J.A.; Trigoni, N.; Markham, A. See Through Smoke: Robust Indoor Mapping with Low-cost mmWave Radar. arXiv 2020, arXiv:1911.00398.

32. Chalhoub, J.; Ayer, S.K.; McCord, K.H. Augmented Reality to Enable Users to Identify Deviations for Model Reconciliation. Buildings 2021, 11, 77. [CrossRef]

33. Mahami, H.; Nasirzadeh, F.; Hosseininaveh Ahmadabadian, A.; Nahavandi, S. Automated Progress Controlling and Monitoring Using Daily Site Images and Building Information Modelling. Buildings 2019, 9, 70. [CrossRef]

34. Masiero, A.; Fissore, F.; Guarnieri, A.; Pirotti, F.; Visintini, D.; Vettore, A. Performance Evaluation of Two Indoor Mapping Systems: Low-Cost UWB-Aided Photogrammetry and Backpack Laser Scanning. Appl. Sci. 2018, 8, 416. [CrossRef]

35. Wang, M.; Wang, C.C.; Sepasgozar, S.; Zlatanova, S. A Systematic Review of Digital Technology Adoption in Off-Site Construction: Current Status and Future Direction towards Industry 4.0. Buildings 2020, 10, 204. [CrossRef]

36. Abdul Shukor, S.; Wong, R.; Rushforth, E.; Basah, S.; Zakaria, A. 3D terrestrial laser scanner for managing existing building. J. Teknol. 2015, 76. [CrossRef]

37. Otero, R.; Lagüela, S.; Garrido, I.; Arias, P. Mobile indoor mapping technologies: A review. Autom. Constr. 2020, 120, 103399. [CrossRef]

38. Schuhmacher, S.; Böhm, J. Georeferencing of Terrestrial Laserscanner Data for Applications in Architectural Modeling. 2005. Available online: https:/ / elib.uni-stuttgart.de/bitstream/11682/3766/1/schuhmacher05_venedig.pdf (accessed on 27 August 2007).

39. Nocerino, E.; Menna, F.; Remondino, F.; Toschi, I.; Rodríguez-Gonzálvez, P. Investigation of Indoor and Outdoor Performance of Two Portable Mobile Mapping Systems; 2017. Available online: https:/ /www.spiedigitallibrary.org/conference-proceedings-of-spie/10 332/103320I/Investigation-of-indoor-and-outdoor-performance-of-two-portable-mobile/10.1117/12.2270761.short?SSO=1 (accessed on 26 August 2021).

40. Zlot, R.; Bosse, M.; Greenop, K.; Jarzab, Z.; Juckes, E.; Roberts, J. Efficiently capturing large, complex cultural heritage sites with a handheld mobile 3D laser mapping system. J. Cult. Herit. 2014, 15, 670-678. [CrossRef]

41. Sepasgozar, S.M.E.; Lim, S.; Shirowzhan, S.; Kim, Y.M. Implementation of As-Built Information Modelling Using Mobile and Terrestrial Lidar Systems. In Proceedings of the International Symposium on Automation and Robotics in Construction; IAARC Publications: Waterloo, ON, Canada, 2014; Volume 31, pp. 1-8.

42. Thomson, C.; Apostolopoulos, G.; Backes, D.; Boehm, J. Mobile Laser Scanning for Indoor Modelling. ISPRS Ann. Photogramm. Remote Sens. Spat. Inf. Sci. 2013, II-5-W2, 289-293. [CrossRef]

43. Samad, A.; Omar, M.; Sahriman, N.; Johan, J.; Ahmat Ruslan, F.; Adnan, R. Implementation of Zebedee 3D Laser Scanner Sensor for Preparation of Strata Title Plan. In Proceedings of the 7th IEEE Control and System Graduate Research Colloquium (ICSGRC), Shah Alam, Malaysia, 8 August 2016; pp. 209-214. [CrossRef]

44. Russhakim, N.a.S.; Ariff, M.F.M.; Majid, Z.; Idris, K.M.; Darwin, N.; Abbas, M.A.; Zainuddin, K.; Yusoff, A.R. The Suitability of Terrestrial Laser Scanning For Building Survey And Mapping Applications. Int. Arch. Photogramm. Remote Sens. Spat. Inf. Sci. 2019, XLII-2-W9, 663-670. [CrossRef]

45. Nikoohemat, S.; Koeva, M.; Oude Elberink, S.J.; Lemmen, C.H.J. Change Detection From Point Clouds To Support Indoor 3d Cadastre. Int. Arch. Photogramm. Remote Sens. Spat. Inf. Sci. 2018, XLII-4, 451-457. [CrossRef]

46. Micoli, L.; Barsanti, S.G.; Malik, U.; Guidi, G. 3D data integration for the digital reconstruction of cultural heritage monuments. IOP Conf. Ser. Mater. Sci. Eng. 2018, 364, 012043. [CrossRef]

47. Altuntas, C.; Yildiz, F.; Scaioni, M. Laser Scanning and Data Integration for Three-Dimensional Digital Recording of Complex Historical Structures: The Case of Mevlana Museum. ISPRS Int. J. Geo-Inf. 2016, 5, 18. [CrossRef]

48. Wen, C.; Sun, X.; Hou, S.; Tan, J.; Dai, Y.; Wang, C.; Li, J. Line Structure-Based Indoor and Outdoor Integration Using Backpacked and TLS Point Cloud Data. IEEE Geosci. Remote Sens. Lett. 2018, 15, 1790-1794. [CrossRef]

49. Serrano, D.; Haag, M.; Dill, E.; Vilardaga, S.; Duan, P. Seamless Indoor-Outdoor Navigation for Unmanned Multi-Sensor Aerial Platforms. Int. Arch. Photogramm. Remote Sens. Spat. Inf. Sci. 2014, 40. [CrossRef]

50. Ellul, C.; Boyes, G.; Thomson, C.; Backes, D. Towards Integrating BIM and GIS-An End-to-End Example from Point Cloud to Analysis. In Lecture Notes in Geoinformation and Cartography; 2017; pp. 495-512. Available online: https://link.springer.com/ chapter/10.1007\%2F978-3-319-25691-7_28 (accessed on 26 August 2021)

51. Sammartano, G.; Spanò, A. Point clouds by SLAM-based mobile mapping systems: Accuracy and geometric content validation in multisensor survey and stand-alone acquisition. Appl. Geomat. 2018, 10, 317-339. [CrossRef]

52. Chiabrando, F.; Sammartano, G.; Spanò, A.; Spreafico, A. Hybrid 3D Models: When Geomatics Innovations Meet Extensive Built Heritage Complexes. ISPRS Int. J. Geo-Inf. 2019, 8, 124. [CrossRef]

53. Vanneschi, C.; Eyre, M.; Francioni, M.; Coggan, J. The Use of Remote Sensing Techniques for Monitoring and Characterization of Slope Instability. Procedia Eng. 2017, 191, 150 [CrossRef] 
54. Otakaari 4. Available online: Https:/ / www.aalto.fi/en/locations/otakaari-4 (accessed on 23 June 2021).

55. ZEB Horizon: SLAM LiDAR for 3D Mapping with Drones. Available online: Https://geoslam.com/solutions/zeb-horizon/ (accessed on 23 June 2021).

56. Bosse, M.; Zlot, R.; Flick, P. Zebedee: Design of a Spring-Mounted 3-D Range Sensor with Application to Mobile Mapping. IEEE Trans. Robot. 2012, 28, 1104-1119. [CrossRef]

57. Frangez, V.; Kramis, B.; Hübscher, F.; Baumann, A. Comparison of Three Innovative Technologies for 3D-Acquisition, Modelling, and Visualization of an Underground Mine. In Proceedings of the International Federation of Surveyors (FIG) Congress 2018, Istanbul, Turkey, 6-11 May 2018.

58. Cabo, C.; Del Pozo, S.; Rodríguez-Gonzálvez, P.; Ordóñez, C.; González-Aguilera, D. Comparing Terrestrial Laser Scanning (TLS) and Wearable Laser Scanning (WLS) for Individual Tree Modeling at Plot Level. Remote Sens. 2018, 10, 540. [CrossRef]

59. Hyyppä, E.; Hyyppä, J.; Hakala, T.; Kukko, A.; Wulder, M.A.; White, J.C.; Pyörälä, J.; Yu, X.; Wang, Y.; Virtanen, J.P.; et al. Under-canopy UAV laser scanning for accurate forest field measurements. ISPRS J. Photogramm. Remote Sens. 2020, 164, 41-60. [CrossRef]

60. Zlot, R.; Bosse, M. Three-Dimensional Mobile Mapping of Caves. J. Cave Karst Stud. 2014, 76, 191-206. [CrossRef]

61. Dewez, T.J.B.; Yart, S.; Thuon, Y.; Pannet, P.; Plat, E. Towards cavity-collapse hazard maps with Zeb-Revo handheld laser scanner point clouds. Photogramm. Rec. 2017, 32, 354-376. [CrossRef] 